\title{
Nd:YAG Lasers Treating of Carious Lesion and Root Canal In Vitro
}

\author{
Danqing Xia, ${ }^{1,2}$ Zenggui Mo, ${ }^{3}$ Gang Zhao, ${ }^{4}$ Fei Guo, ${ }^{1,2}$ Chao You, ${ }^{1,2}$ Ze Chen, ${ }^{1,2}$ Xiao Zhu, ${ }^{1,2}$ \\ Zhengjia Li, ${ }^{1,2}$ Di Chen, ${ }^{1,2}$ and Xiaohong Fan ${ }^{1,2}$ \\ ${ }^{1}$ Wuhan National Laboratory for Optoelectronics, Huazhong University of Science and Technology, Hubei 430074, Wuhan, China \\ ${ }^{2}$ College of Optoelectronics Science and Engineering, Huazhong University of Science and Technology, Hubei 430074, Wuhan, China \\ ${ }^{3}$ Affiliated Hospital, Huazhong University of Science and Technology, Hubei 430074, Wuhan, China \\ ${ }^{4}$ Department of Stomatology, The People's Hospital of Huangzhou District, Hubei 438000, Huanggang, China
}

Correspondence should be addressed to Xiaohong Fan, xhfan@mail.hust.edu.cn

Received 14 February 2012; Revised 29 April 2012; Accepted 7 May 2012

Academic Editor: Timon Cheng-Yi Liu

Copyright (๑) 2012 Danqing Xia et al. This is an open access article distributed under the Creative Commons Attribution License, which permits unrestricted use, distribution, and reproduction in any medium, provided the original work is properly cited.

Dental caries is a transmissible bacterial disease process, with cavities at the end, and caused by acids from bacterial metabolism. The essence of dental treatment is to clean and disinfect bacterial contamination from the tooth. In this work, we tried to demonstrate the cleaning and disinfecting effects of Nd:YAG laser irradiation on dental carious lesion and root canal in vitro. Acousto-optic Q-switched quasicontinuous and $\mathrm{Cr}^{3+}$ :YAG crystal Q-switched pulse Nd:YAG lasers were employed to treat caries lesion and the root canal, respectively. Results showed that acousto-optic Q-switched quasicontinuous Nd:YAG laser irradiation and $\mathrm{Cr}^{3+}$ :YAG crystal Q-switched pulse Nd:YAG laser irradiation could rapidly clean decayed material and bacterial contamination from dental carious lesion and the narrow tail end of root canal with minimally invasive in vitro, respectively. It was concluded that acousto-optic Q-switched quasicontinuous laser irradiation may be a rapid and effective alternative caries treatment, and $\mathrm{Cr}^{3+}: \mathrm{YAG}$ crystal Q-switched pulse Nd:YAG laser irradiation may be an effective method for canal cleaning and disinfecting during root canal therapy.

\section{Introduction}

Dental caries is the most prevalent disease among preschool children (early child caries) [1], although it has been reported to be a declining incidence worldwide in the last decades [2]. Almost $76 \%$ of children aged 5 in China [3] and about $30 \%$ aged 2 to 5 in America [4] were affected by dental caries, and the percent is in rise. Dental caries is a transmissible bacterial disease process and caused by acids from bacterial metabolism. Cariogenic bacterial, feeding on the carbohydrates in food, can be easily transferred to babies from mothers or caregivers before the teeth erupts [5-7] and colonize teeth as dental plaque when teeth erupts. Acids produced by bacteria in dental plaque rapidly diffuse in all directions through the pores of enamel or dentine and into the underlying tissue to dissolve acid soluble mineral, and finally cavity was formed in the tooth after many months or years. Usually, dental caries can be inhibited and even reversed in its early stages of process by removing cariogenic bacteria from teeth. Unfortunately, it is often not self-limiting and progresses without proper care until the tooth is destroyed with cavities. Then, it is more difficult to remove bacteria from rough, cavitated surfaces, which quicken the dental caries progress. In addition, bacterial contamination in root canal is also considered the principle etiologic factor for the development of pulpal and periapical lesions $[7,8]$.

Dental treatment can prevent and inhibit the dental caries by cleaning and disinfecting the bacterial contamination in tooth or enhancing the caries resistance of tooth at the very beginning of dental caries process [9]. For those small lesions, enhancing the caries resistance to prevent caries normally by topical fluoride is the focal point of treatment [10]. Mentionable, laser has been widely used in dentistry for decades, which is well known to increase enamel resistance to acids dissolving, and Nd:YAG laser irradiation combined with topical fluoride treatment can induce an even greater increase in caries resistance [11]. However, there is no doubt that removal of plaque is the most effective way to help prevent periodontal disease and caries processing due to the 


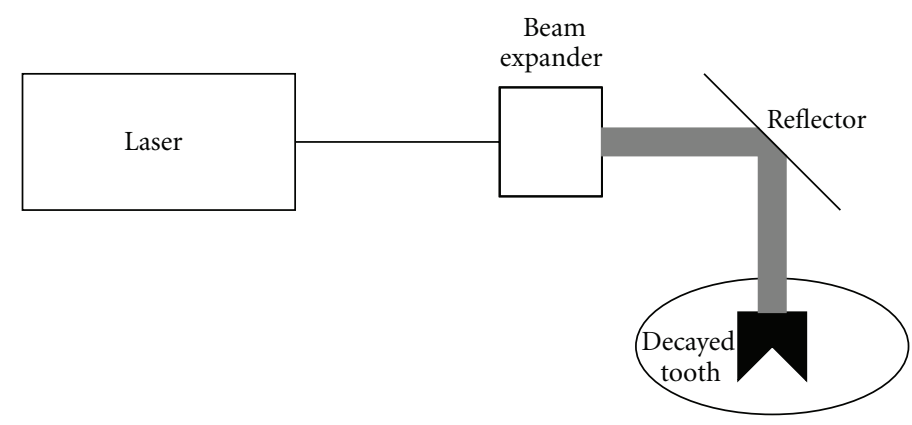

FIGURE 1: The sketch of quasicontinuous laser system.

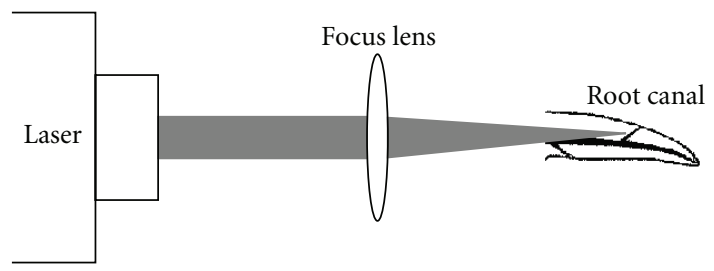

Figure 2: The sketch of Q-switched laser system.

well-known harm of fluoride $[12,13]$. Many types of lasers have been used for dental caries prevention, and Nd:YAG laser is the most studied one [11, 14-16]. For larger lesions, cleaning and disinfecting the bacterial contamination in tooth to inhibit the caries is the essence of treatment. Aiming to preserve tooth structures and prevent further destruction of the tooth, large portions of decayed material is removed from the tooth by a dental drill and cleaned carefully by a spoon during traditional caries treatment [17], which is with great invasive and painful even terrifying for patient especially preschool children. Moreover, it is impossible to completely remove pulp tissue, debris, and bacteria which cause secondary caries and pain.

Thus, it is necessary to develop an alternative caries treatment, which can remove the bacterial containment painless with minimally invasive. Present work is to demonstrate the ability of acousto-optic Q-switched quasicontinuous $\mathrm{Nd}$ :YAG lasers and $\mathrm{Cr}^{3+}$ :YAG crystal Q-switched pulse $\mathrm{Nd}$ :YAG lasers in cleaning of decayed material (pulp and others) speedily and disinfecting of bacteria completely of human tooth in vitro. Laser irradiation treatment may be an ideal alternative dental caries treatment especially preschool children aged 2 to 5 years.

\section{Materials and Methods}

2.1. Laser System. Quasicontinuous laser beam with wavelength of $1064 \mathrm{~nm}$ provided by an acousto-optic Q-switched Nd:YAG laser system (Figure 1) was vertically delivered to the carious lesion on tooth surface. Comparing to continuouswave laser, acousto-optic Q-switched quasicontinuous laser has a relative higher peak power, which is better for bacterial disinfecting, and a shorter half-height pulse width, which will be beneficial to avoid overheating. This laser system was normally set with $30 \mathrm{~W}$ peak average output power and $600 \mathrm{~Hz}$ frequency. The peak power density of the laser irradiation was about $152.86 \mathrm{~W} / \mathrm{cm}^{2}$ with a diameter of about $0.5 \mathrm{~cm}$ and beam area of approximate $0.196 \mathrm{~cm}^{2}$.

The Q-switched laser beam, provided by a $\mathrm{Cr}^{3+}: \mathrm{YAG}$ crystal Q-switched laser system (Figure 2), was vertically focused on the canal directly. The focused Q-switched pulse laser irradiation has a smaller diameter, a higher peak power, and energy density, which is better for cleaning and disinfecting of narrow canal gap. This laser system was normally set with $100 \mathrm{~mJ}$ single-pulse energy, $1 / 3 / 5 \mathrm{~Hz}$ frequency, and about $100 \mathrm{~ns}$ half-height pulse width.

2.2. Materials. Human teeth with carious lesion on crown surface (one was shown at Figure 3(a)) were collected from the affiliated hospital to reveal the cleaning and disinfecting effect of quasicontinuous acousto-optic Q-switched Nd:YAG laser irradiation for decayed material from caries lesion. The tail end of root canal (one is shown at Figure 3(b)), which is the most narrow part and the difficult point of cleaning and disinfecting in root canal system, was prepared in the affiliated hospital to reveal the cleaning and disinfecting effect of $\mathrm{Cr}^{3+}$ :YAG crystal Q-switched laser irradiation for tissue and bacterial contamination in tooth canal.

2.3. Experiment. To demonstrate the cleaning effect of laser treatment, carious lesion tooth samples were exposed to acousto-optic Q-switched quasicontinuous laser irradiation, and tooth canal samples were exposed to $\mathrm{Cr}^{3+}$ :YAG crystal Q-switched pulse Nd:YAG laser irradiation, respectively. The cleaning efficiency is evaluated from the difference between pictures of lesion surface before and after laser treated. The disinfecting effect and efficiency of laser treatment is evaluated from the colony counts loss of samples. The experiment samples were scrubbed by swabs with sterile physiological saline before and after laser treatment, respectively. Then, the 


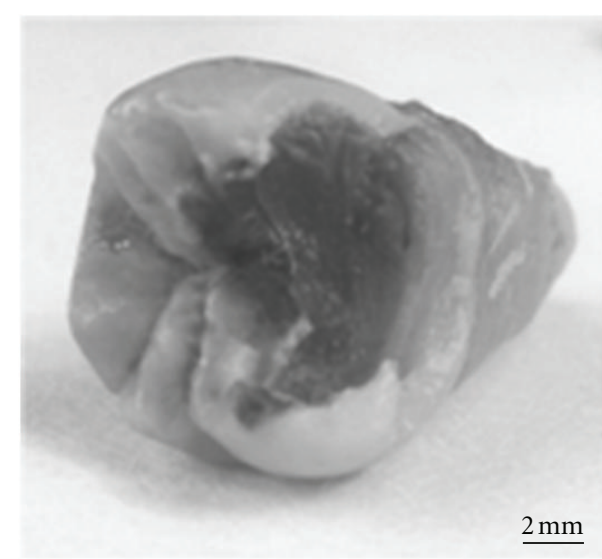

(a)

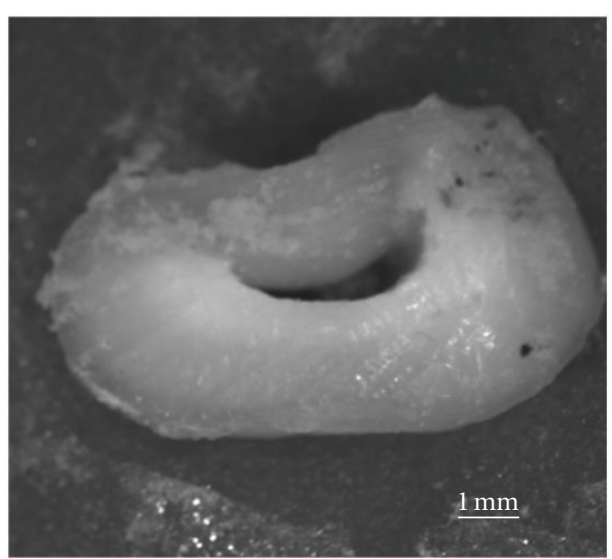

(b)

FIgURE 3: Stereomicroscope images of (a) tooth with carious lesion and (b) tail end of root canal.

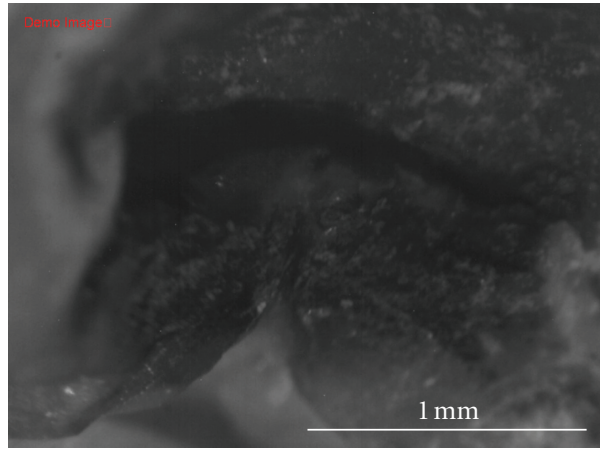

(a)

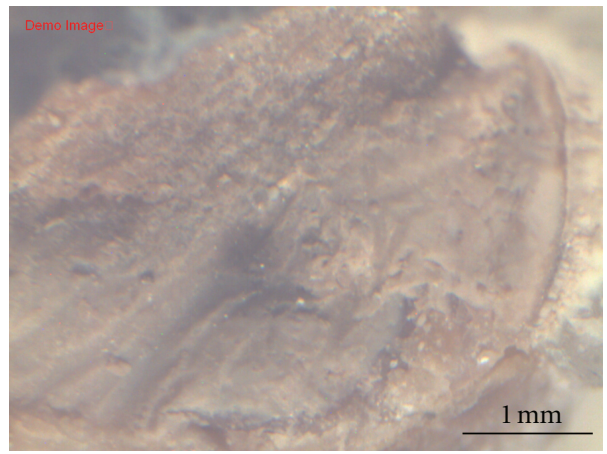

(b)

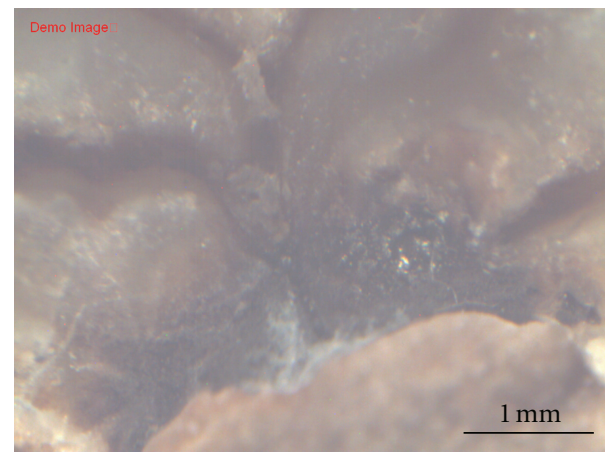

(c)

FIGURE 4: Stereomicroscope images of decayed tooth surface (a) before and (b, c) after acousto-optic Q-switched Nd:YAG quasicontinuous laser treatment.

infected physiological saline of each sample was inoculate to 3 parallel agar dishes and cultivated at $37^{\circ} \mathrm{C}$ for 24 hours. In order to prevent the bacterial contamination from hands, the medical rubber gloves were necessary during the whole experiment.

\section{Results and Discussion}

3.1. Cleaning and Disinfecting Effects. Figure 4 showed the stereomicroscope images of carious lesion on the surface of tooth before (Figure 4(a)) and after laser treatment (Figures $4(\mathrm{~b})$ and $4(\mathrm{c}))$. It was clear that decayed material in caries lesion was cleared away by laser irradiation without any visible damages to surrounding normal tooth tissues after no more than 2-second quasicontinuous laser irradiation. However, there was little carbonization in the treated area, carbonization indicated that laser treatment with less power density or shorter irradiation time would be better for caries material cleaning. The obvious change of caries in tooth before and after laser treatment indicated that the 


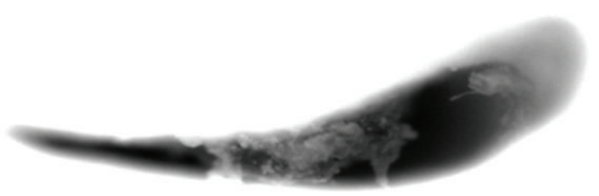
$1 \mathrm{~mm}$

(a)

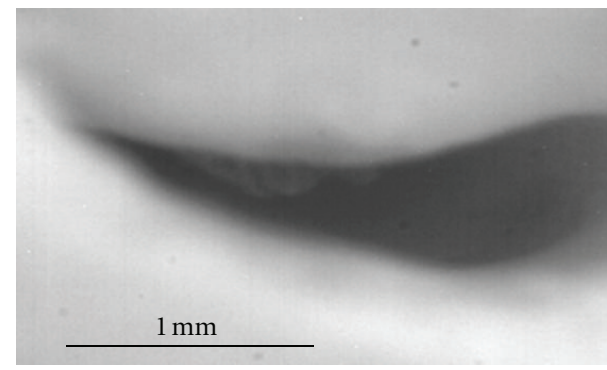

(c)

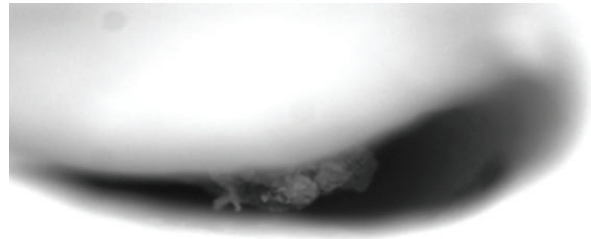

$1 \mathrm{~mm}$

(b)

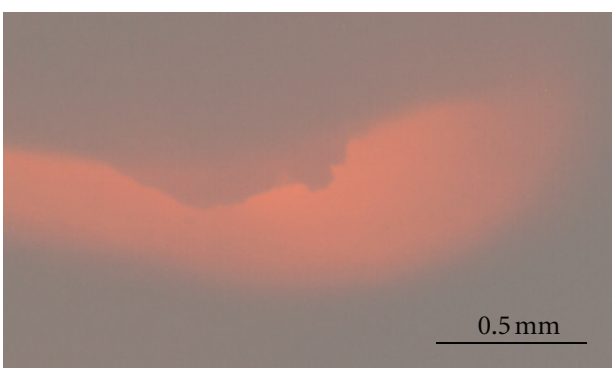

(d)

FIGURE 5: Stereomicroscope images of organisms in untreated (a), 20 pulses (b), and 40 pulses (c, d) laser irradiation-treated root canal gap.

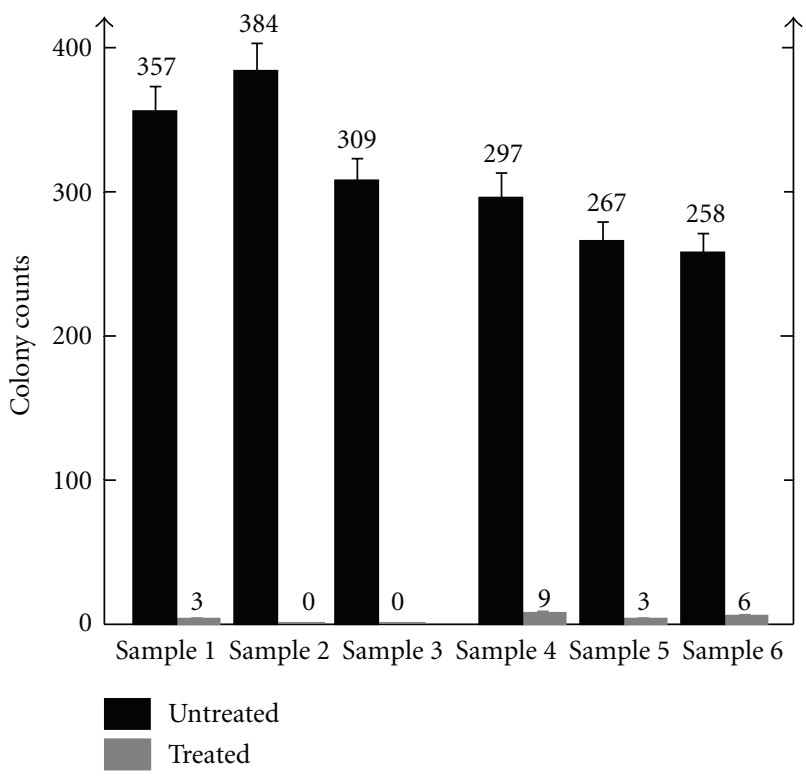

Figure 6: The colony counts of carious lesions (samples 1-3) and root canals (samples 4-6).

acousto-optic Q-switched Nd:YAG quasicontinuous laser irradiation was a speedy and efficient cleaning method and treatment for carious lesion.

Figure 5 shows the images of root canal sample before (Figure 5(a)) and after 20 pulses (Figure 5(b)), 40 pulses laser-treated by $\mathrm{Cr}^{3+}$ :YAG crystal Q-switched laser. (Figures 5(c) and 5(d)) comparing Figure 5(a) to Figure 5(b), it was clear that much portion of the tissue in canal was removed and almost cleared away after 40-pulse laser treatment. Particularly, there was almost no byproduct in tooth canal after laser treatment according to Figures 5(c) and 5(d).
These results indicated that $\mathrm{Cr}^{3+}: \mathrm{YAG}$ Q-Switched laser irradiation might clean up the root canal after more than 40 pulses, and $\mathrm{Cr}^{3+}:$ YAG Q-switched laser treatment may be an ideal method for tooth canal cleaning.

The colony counts of experiment tooth samples before and after laser treatment were shown in Figure $6(P<0.05)$. Samples 1-3 refer to the tooth samples with carious lesion, and samples 4-6 refer to root canal samples. According to decrement colony counts of untreated and treated samples, the disinfecting effect was obvious and the disinfecting efficiency was high, approximately $100 \%$ and $98.5 \%$ for 
caries and root canal disinfecting, respectively. The results indicated that Q-switched laser irradiation treatment was a very effective disinfecting method for caries treatment, even root canal.

\section{Discussions}

It is an advantage to choose laser beam with less power density, or less repeated frequency for tooth treatment, because the carbonization showed in Figure 4(b) was due to overheat of acousto-optic Q-switched quasicontinuous laser irradiation. In addition, those experimental samples used in this work were only with carious lesion on the crown surface, but majority of patients in clinics have caries lesion deeply inside the tooth. Thus our further work will aim at laser holing for cleaning material in deep carious lesion.

Acousto-optic Q-switched quasicontinuous laser irradiation with big beam size, high average energy density, and repeated frequency was effective for caries lesion treatment, and $\mathrm{Cr}^{3+}$ :YAG crystal Q-switched laser irradiation with smaller beam size, shorter pulse width, and higher peak energy density is effective for root canal treatment without any obvious byproducts as carbonization appeared in caries lesion laser treatment. Both acousto-optic Q-switched quasicontinuous laser irradiation and $\mathrm{Cr}^{3+}$ :YAG crystal Qswitched laser irradiation had advantages over each other in dental caries treatment and had common advantages such as no pain, no vibrating, overtraditional treatment with drill and spoon. Laser irradiation treatment was very friendly for patient especially for the preschool children patients. It will be a good alternative for early child caries inhibition and readiness to be accepted by child patients.

\section{Conclusions}

In conclusion, acousto-optic Q-switched quasicontinuous laser irradiation may be a rapid and effective alternative caries treatment, and $\mathrm{Cr}^{3+}$ :YAG crystal Q-switched pulse $\mathrm{Nd}$ :YAG laser irradiation may be an effective method for canal cleaning and disinfecting during root canal therapy.

\section{Acknowledgments}

The authors gratefully appreciate the generous help of laser system and stereomicroscope from Professors Xiao Zhu and Pengcheng Li in Wuhan National Laboratory for Optoelectronics.

\section{References}

[1] J. A. Aas, A. L. Griffen, S. R. Dardis et al., "Bacteria of dental caries in primary and permanent teeth in children and young adults," Journal of Clinical Microbiology, vol. 46, no. 4, pp. 1407-1417, 2008.

[2] R. A. Bagramian, F. Garcia-Godoy, and A. R. Volpe, "The global increase in dental caries. A pending public health crisis," American Journal of Dentistry, vol. 22, no. 1, pp. 3-8, 2009.
[3] B. A. Dye, S. Tan, V. Smith et al., "Trends in oral health status: United States, 1988-1994 and 1999-2004," Vital and Health Statistics, no. 248, pp. 1-92, 2007.

[4] H. Y. Wang, P. E. Petersen, J. Y. Bian, and B. X. Zhang, "The second national survey of oral health status of children and adults in China," International Dental Journal, vol. 52, no. 4, pp. 283-290, 2002.

[5] J. D. B. Featherstone, "Dental caries: a dynamic disease process," Australian Dental Journal, vol. 53, no. 3, pp. 286-291, 2008.

[6] R. J. Berkowitz, "Acquisition and transmission of mutans streptococci," Journal of the California Dental Association, vol. 31, no. 2, pp. 135-138, 2003.

[7] Y. Kawashita, M. Kitamura, and T. Saito, "Early childhood caries," International Journal of Dentistry, vol. 2011, Article ID 725320, 7 pages, 2011.

[8] A. S. Garcez, S. C. Nuñez, M. R. Hamblin, and M. S. Ribeiro, "Antimicrobial effects of photodynamic therapy on patients with necrotic pulps and periapical lesion," Journal of Endodontics, vol. 34, no. 2, pp. 138-142, 2008.

[9] C. H. Hu, J. He, R. Eckert et al., "Development and evaluation of a safe and effective sugar-free herbal lollipop that kills cavity-causing bacteria," International Journal of Oral Science, vol. 3, no. 1, pp. 13-20, 2011.

[10] R. R. Breaker, "New insight on the response of bacteria to fluoride," Caries Research, vol. 46, no. 1, pp. 78-81, 2012.

[11] D. M. Zezell, H. G. D. Boari, P. A. Ana, C. D. P. Eduardo, and G. L. Powell, "Nd:YAG laser in caries prevention: a clinical trial," Lasers in Surgery and Medicine, vol. 41, no. 1, pp. 31-35, 2009.

[12] J. M. Broadbent, W. M. Thomson, J. V. Boyens, and R. Poulton, "Dental plaque and oral health during the first 32 years of life," Journal of the American Dental Association, vol. 142, no. 4, pp. 415-426, 2011.

[13] R. P. Allaker and C. W. I. Douglas, "Novel anti-microbial therapies for dental plaque-related diseases," International Journal of Antimicrobial Agents, vol. 33, no. 1, pp. 8-13, 2009.

[14] P. Rechmann, D. Fried, C. Q. Le et al., "Caries inhibition in vital teeth using 9.6- $\mu \mathrm{m} \mathrm{CO}$-laser irradiation," Journal of Biomedical Optics, vol. 16, no. 7, Article ID 071405, 2011.

[15] C. S. Castellan, A. C. Luiz, L. M. Bezinelli et al., "In vitro evaluation of enamel demineralization after Er:YAG and Nd:YAG laser irradiation on primary teeth," Photomedicine and Laser Surgery, vol. 25, no. 2, pp. 85-90, 2007.

[16] H. G. D. Boari, P. A. Ana, C. P. Eduardo, G. L. Powell, and D. M. Zezell, "Absorption and thermal study of dental enamel when irradiated with Nd:YAG laser with the aim of caries prevention," Laser Physics, vol. 19, no. 7, pp. 1463-1469, 2009.

[17] http://en.wikipedia.org/wiki/Dental_caries . 


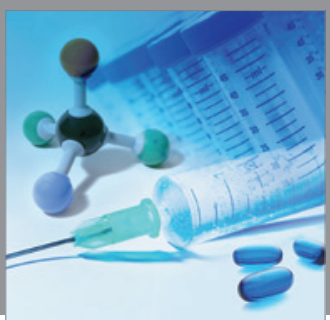

International Journal of

Medicinal Chemistry

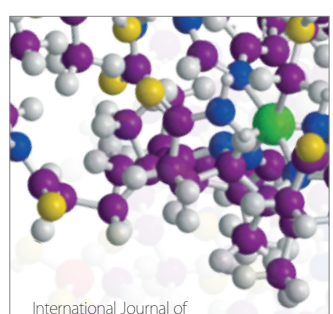

Carbohydrate Chemistry

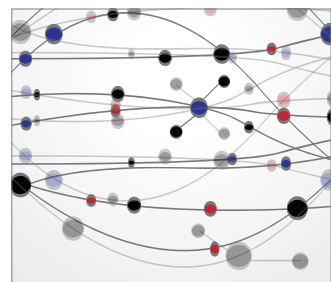

The Scientific World Journal
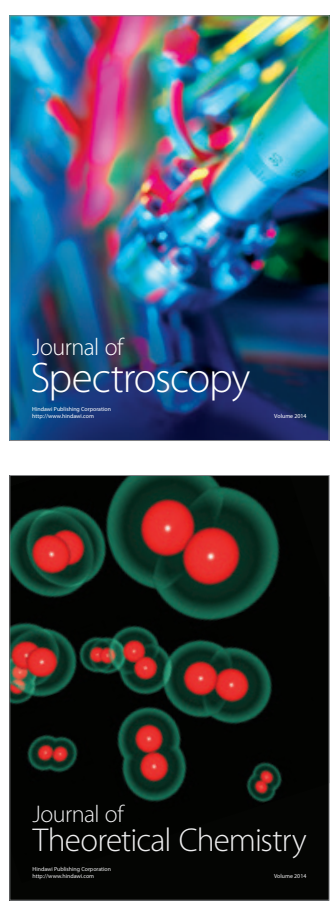
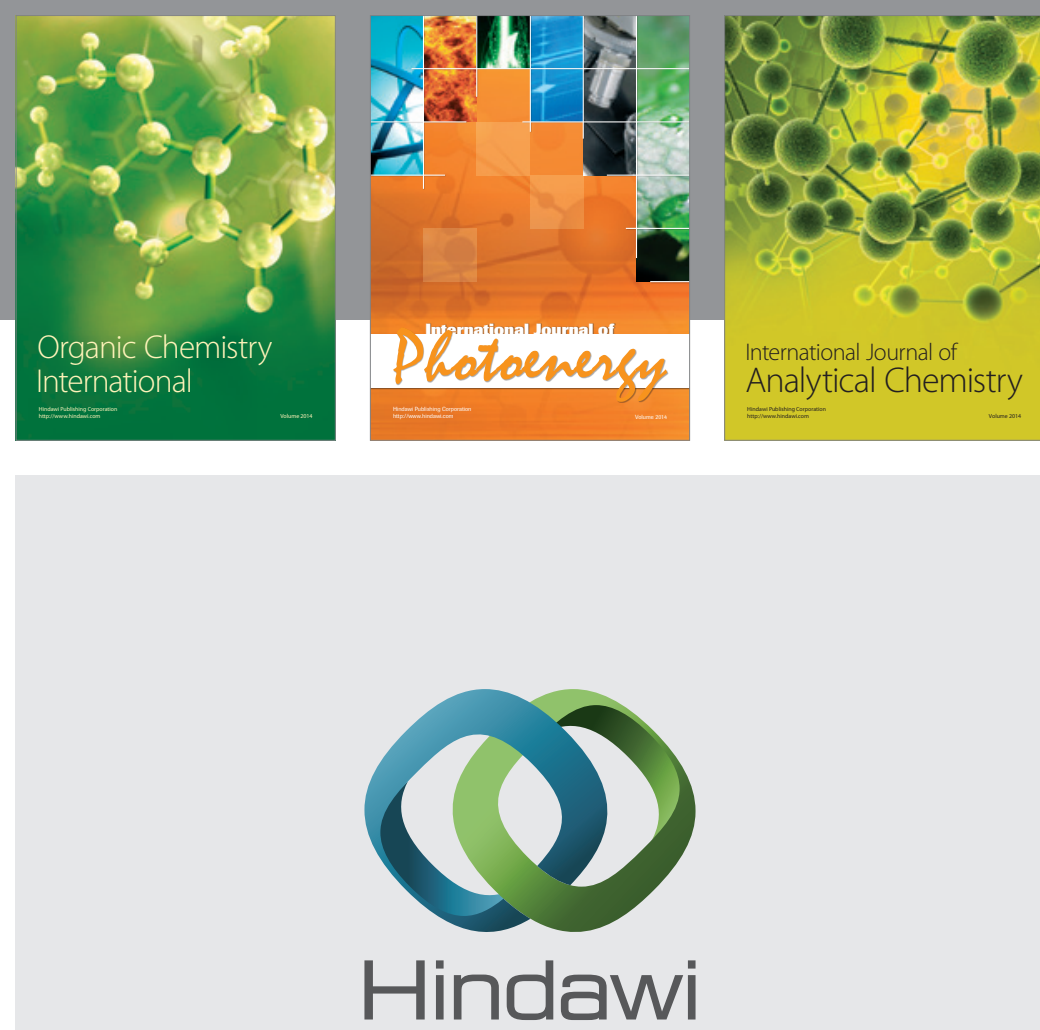

Submit your manuscripts at

http://www.hindawi.com
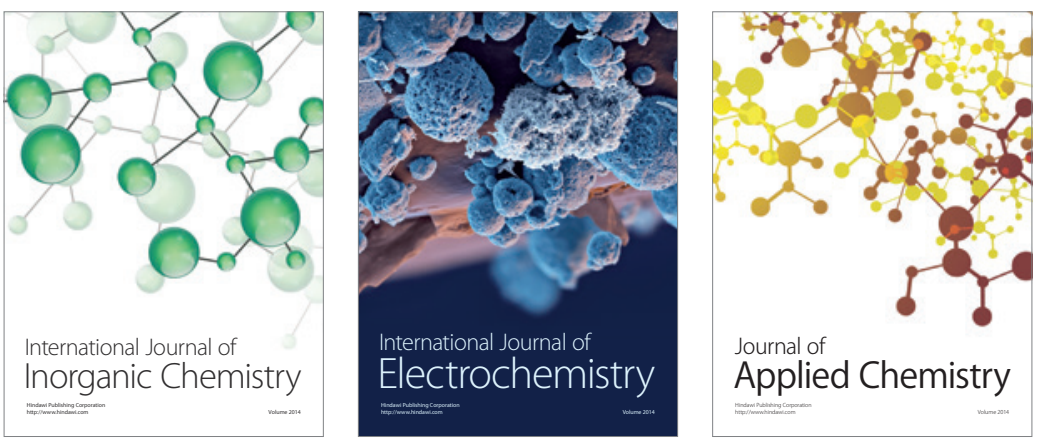

Journal of

Applied Chemistry
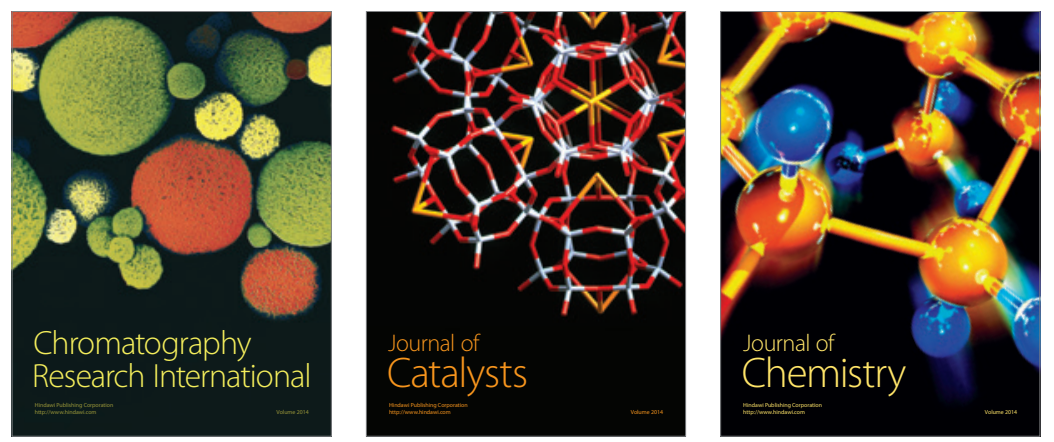
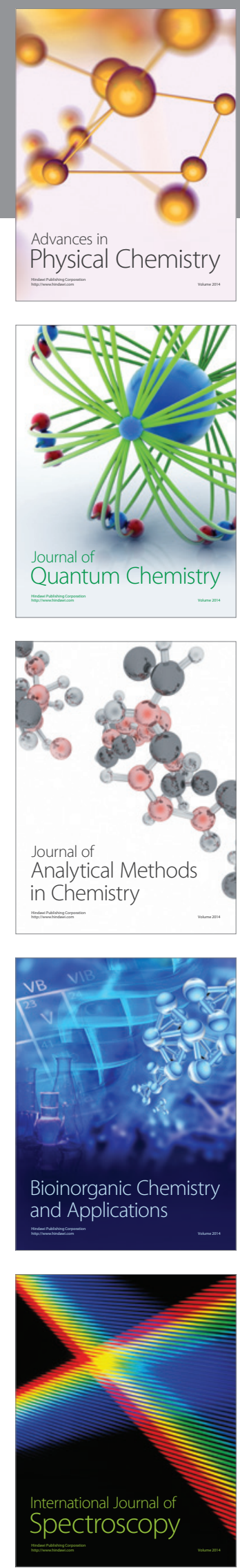